\title{
ANÁLISE JUSLABORAL DA RELAÇÃO DE TRABALHO ENTRE MOTORISTAS POR APLICATIVO E A EMPRESA UBER: ASPECTOS E CONSEQUÊNCIAS SOCIOJURÍDICOS
}

\author{
Murilo Martins ${ }^{1}$ \\ Victor Hugo de Almeida ${ }^{2}$
}

\section{RESUMO}

A empresa Uber deu ensejo à formação de uma nova classe de trabalhadores, os motoristas por aplicativo. A natureza da relação dos motoristas com a empresa é controversa, tendo motivado ações trabalhistas para a discussão da existência de vínculo empregatício. Propõe-se analisar essa relação, além de seus impactos juslaborais tendentes ou não à precarização dos direitos trabalhistas. Adotou-se, como método de procedimento, a pesquisa bibliográfica e a análise de julgados; e, como método de abordagem, o dedutivo, visando verificar a existência ou não de relação de emprego, bem como aventar possíveis consequências jurídicas e sociais decorrentes desse modelo de trabalho.

Palavras-chave: Direitos trabalhistas; Economia colaborativa; Precarização; Relação trabalhista; Uber.

\section{LEGAL-LABOR ANALYSIS OF THE WORK RELATIONSHIP BETWEEN DRIVERS BY APPLICATION AND THE UBER COMPANY: SOCIO-LEGAL ASPECTS AND CONSEQUENCES}

\begin{abstract}
Uber gave rise to the formation of a new class of workers, the drivers by application. The nature of their relationship with the company is controversial, having motivated labor actions to discuss the work relationship. It is proposed to analyze this relationship and its legal-labor impacts, tending or not to the precariousness of labor rights. As a method of procedure, a bibliographical research and analysis of legal decision was adopted; and, as a method of approach, the deductive, aiming to verify the existence or not of the work relationship, and the possible legal and social consequences of this work model.
\end{abstract}

Keywords: Labor rights; Sharing economy; Precariousness; Work relationship; Uber.

\section{INTRODUÇÃO}

\footnotetext{
${ }^{1}$ Mestrando e Graduado em Direito pela Faculdade de Ciências Humanas e Sociais, da Universidade Estadual Paulista "Júlio de Mesquita Filho" - UNESP, Campus de Franca.

${ }^{2}$ Doutor pela Faculdade de Direito da Universidade de São Paulo. Mestre pela Faculdade de Filosofia, Ciências e Letras de Ribeirão Preto da Universidade de São Paulo. Docente na Faculdade de Ciências Humanas e Sociais da Universidade Estadual Paulista Júlio de Mesquita Filho - UNESP/Franca, Graduação e Pós-Graduação. Membro Pesquisador do Instituto Brasileiro de Direito Social Cesarino Júnior, Seção Brasileira da Societé Internacionale de Droit du Travail et de la Sécurité Sociale.
} 
Com o advento do Século XXI, o trabalho passa por mudanças desencadeadas pela chamada Terceira Revolução Tecnológica. Segundo Maurício Godinho Delgado (2015, p. 38), essas alterações agravaram a redução de postos de trabalho em diversos segmentos econômicos, em especial na indústria, o que ocasionou no aprofundamento do desemprego deflagrado pela crise econômica de meados dos anos 1970. Com o surgimento de novas formas de organização, o trabalho é revestido de uma flexibilidade antes inexistente, permitindo a redução de mão de obra, além da possibilidade de ser realizado à distância ou por intermédio das diversas tecnologias desenvolvidas.

O desenvolvimento do fenômeno da sharing economy, também conhecido por economia colaborativa, contribui com esse processo, ao pressupor uma maior colaboração entre as pessoas, criando novas interações e relações na sociedade. A economia colaborativa pauta-se por uma melhor utilização dos recursos, tendo como ideia central o compartilhamento.

Dentro do fenômeno da sharing economy, surgem, no Vale do Silício nos Estados Unidos, empresas com ideias para as mais diversas necessidades da sociedade, como hospedagem e transporte, atentando-se para a questão do compartilhamento dos recursos. Uma dessas empresas é a Uber, que propõe o compartilhamento de veículos por pessoas comuns, com o auxílio de uma plataforma digital desenvolvida pela empresa.

Apesar de se originar da economia de compartilhamento, a empresa Uber desenvolveu um modelo organizacional próprio, que acaba por se distanciar das ideias originais da sharing economy, ao se pautar pelo lucro. Com o modelo adotado, os motoristas não são apenas compartilhadores de veículos com outras pessoas, mas sim, trabalhadores de uma nova categoria, os chamados motoristas por aplicativo, que utilizam da plataforma digital da empresa Uber como fonte de renda (primária ou não).

O modelo de trabalho que a Uber acaba por gerar tem impactado nos últimos anos o setor de transportes de cidades por todo o globo. O modelo organizacional proposto, no entanto, levanta questões tanto quanto à sua regulação, por atuarem em um ramo já existente (o dos taxistas), quanto pelas tensões geradas no âmbito trabalhista, uma vez que ainda é incerta a natureza do trabalho desenvolvido pela categoria dos motoristas por aplicativo.

Sem uma definição, os motoristas por aplicativo acabam por ficar desamparados juridicamente, o que pode representar uma precarização do trabalho desenvolvido. Inexistindo direitos e garantias assegurados, a força de trabalho desses motoristas pode acabar sendo 
explorada sem limitações, ocasionando violações a direitos fundamentais, como, por exemplo, à dignidade da pessoa humana.

O presente trabalho propõe analisar a questão da relação de trabalho existente entre os motoristas por aplicativo e a empresa Uber, além dos impactos juslaborais decorrentes desse modelo de trabalho, tendentes ou não à precarização dos direitos trabalhistas.

Adotou-se, como método de procedimento, o levantamento por meio da técnica de pesquisa bibliográfica em materiais publicados (doutrinas, legislação, notícias veiculadas em sítios eletrônicos, artigos científicos, entre outros). Também foram analisados dois julgados decorrentes de ações ajuizadas perante a Justiça do Trabalho, precursoras no país quanto à pretensão de reconhecimento de vínculo de emprego entre motoristas e a empresa Uber. E, como método de abordagem, adotou-se o método dedutivo, de modo a concluir, a partir da organização dessa forma trabalho à luz do sistema juslaboral brasileiro, pela existência ou não de relação de emprego, bem como aventar possíveis consequências jurídicas e sociais decorrentes desse modelo de trabalho.

\section{O MODELO DE ATUAÇÃO DA EMPRESA UBER}

A empresa Uber, fundada em 2009 por Garrett Camp e Travis Kalanick, apresenta uma forma de organização focada no chamado e-hailing, termo de origem inglesa que significa o ato de solicitar transporte privado por meio de um aparelho tecnológico de comunicação, como celulares (KERR, 2015, p. 1). A composição do modelo de atuação da Uber possui três polos essenciais: os passageiros, o motorista parceiro e o aplicativo (plataforma digital fornecida pela empresa, que conecta os motoristas aos passageiros).

A cada viagem realizada através da plataforma, o valor da corrida é calculado e pago pelo passageiro diretamente à empresa por meio do aplicativo, sendo, após esse processo, repassado aos motoristas conforme sua categoria de atuação (UberX ou UberBlack, por exemplo) e a distância percorrida. As categorias possuem diferentes porcentagens, que são retidas pela empresa como forma de pagamento pela utilização dos serviços tecnológicos ofertados (UBER, 2016a).

Para ser um motorista parceiro da Uber são necessários, a princípio, apenas o documento pessoal, a Carteira Nacional de Habilitação $(\mathrm{CNH})$ com a observação "exerce atividade remunerada", e documentos do veículo, que devem seguir diretrizes da empresa. 
Ainda, deve o motorista parceiro possuir seguro de acidentes pessoais (PARCEIROSBR, 2015).

A empresa Uber possui duas políticas que são importantes para o entendimento do trabalho desempenhado pelos motoristas: o sistema de taxa de cancelamentos e o sistema de avaliações (UBER, 2016b).

O sistema de taxa de cancelamentos funciona medindo o número de vezes que o motorista parceiro cancela uma viagem aceita por intermédio do aplicativo. Caso o motorista apresente uma alta taxa de cancelamentos, poderá ser desligado da empresa, sendo impedido de utilizar os serviços fornecidos pela plataforma Uber.

O sistema de avaliação por estrelas é utilizado pela empresa como um controle do nível de qualidade dos serviços fornecidos pelos motoristas parceiros. Por meio de uma via de mão dupla, motorista e passageiro se avaliam com notas (estrelas) de 1 a 5 , de acordo com a experiência que ambos tiveram no trajeto realizado. Para poder continuar utilizado a plataforma da Uber, o motorista precisa apresentar uma nota mínima estipulada pela empresa em cada cidade (UBER, 2016b).

Este modelo de atuação da Uber, como apresentando, tem gerado em todo globo dúvidas quando à natureza do trabalho dos motoristas, em específico, da existência ou não de vínculo de emprego deles com a empresa. Ações trabalhistas para questionar a existência do vínculo foram propostas nos EUA, Inglaterra e, inclusive, no Brasil, com sentenças já proferidas, conforme será analisado adiante.

A Uber se diz uma empresa de tecnologia que apenas fornece a plataforma para os motoristas atuarem (UBER NEWSROOM , 2015). Motoristas, no entanto, questionam essa tese, buscando a declaração de existência de vínculo de emprego, por meio da propositura de ações trabalhistas. Dessa forma, com base no modelo de atuação da empresa Uber, será analisada a seguir a natureza da relação de trabalho existente.

\section{A RELAÇÃo JURÍdiCA dOS MOTORISTAS POR APLICATIVO NO MODELO UBER}

Os motoristas por aplicativo desempenham uma forma de trabalho ainda recente no país. A análise da relação existente, dessa forma, necessita previamente da distinção entre 
relação de trabalho e relação de emprego, para a adequada compreensão da situação apresentada.

Conforme Maurício Godinho Delgado (2007a, p. 285), relação de trabalho é um termo amplo e genérico que abarca todas as modalidades de contratação de trabalho humano. A relação de emprego, no entanto, trata-se de uma das modalidades da relação de trabalho, a ser verificada conforme uma série de fatores determinados pela Consolidação das Leis do Trabalho (CLT).

Os requisitos exigidos para a caraterização do vínculo empregatício são encontrados por meio de uma análise conjunta dos artigos $2^{\circ}$ e $3^{\circ}$, da CLT. Os requisitos são a prestação de trabalho por pessoa física, com pessoalidade, não eventualidade, onerosidade e subordinação da atividade ao poder diretivo do empregador.

A execução do trabalho por pessoa física diz respeito a não prestação de trabalho por uma pessoa jurídica. Se o trabalho é exercido por pessoa jurídica, exclui-se a possibilidade de vínculo empregatício, caracterizando-se, pois, uma relação jurídica civil. Os motoristas da empresa Uber evidentemente são pessoas físicas, o que se confirma pela exigência de documentos pessoais para utilização da plataforma digital.

O requisito da pessoalidade aborda a questão da impossibilidade de substituição do prestador de serviço por outro, tratando-se de contrato intuitu personae. Uma vez que os motoristas da empresa Uber possuem conta pessoal intransferível, que não pode ser utilizada por outro trabalhador, o trabalho realizado por aquele motorista possui pessoalidade.

A não eventualidade, conforme Vólia Bomfim Cassar (2014, p. 261), trata-se da “necessidade permanente, isto é, de não ser o trabalho esporádico ou descontínuo". O motorista da empresa Uber não possui exclusividade com a empresa, podendo se dedicar a outras ocupações e trabalhar com outras plataformas. Além disso, existe a possibilidade de o motorista trabalhar quantos dias e horas desejar, sem limite de jornada mínima ou máxima. A não eventualidade, dessarte, deve ser analisada em cada caso concreto, podendo ou não ser configurada.

Caso configurem-se os requisitos da relação de emprego, com exceção da não eventualidade, tem-se caracterizado o trabalho eventual. Nesta relação de trabalho, o labor é exercido com descontinuidade, pluralidade variável de tomadores de serviços, duração curta e concernente a um evento certo e determinado (DELGADO, 2007a, p. 340). 
O requisito da onerosidade traduz a remuneração quitada pelo empregador em favor do empregado, em decorrência do trabalho prestado. No modelo de trabalho da Uber, a empresa concentra consigo os valores pagos pelos passageiros para depois repassá-los aos motoristas, retendo, portanto, uma porcentagem para si. A onerosidade se configura dessa forma, tendo em consideração que o motorista não paga uma tarifa mensal fixa, por exemplo, para a utilização da plataforma para exercer seu trabalho; ao contrário, a empresa repassa os valores devidos aos motoristas conforme a quantidade de viagens realizadas, com base nas tarifas e porcentagens por ela definidas unilateralmente.

O último requisito para a verificação da existência de vínculo empregatício é a subordinação jurídica. A subordinação, também conhecida por dependência hierárquica, trata da submissão da atividade laboral prestada pelo empregado em favor do empregador, cujo ofício deve sujeitar-se a regras, orientações e normas estabelecidas (CASSAR, 2014, p. 246).

A subordinação, no modelo de trabalho da Uber, pode gerar controvérsias. A subordinação clássica não é suficiente para abarcar as inovações que o trabalho propiciado pela tecnologia apresenta. Isso porque a Uber não determina horas de trabalho, mas possui um código de conduta para seus motoristas e exerce controle de qualidade por meio de uma política de avaliações por estrelas e taxa de cancelamentos, conforme previamente abordado.

A mera existência de uma certa autonomia do trabalhador, como a definição da própria jornada de trabalho, poderia afastar a subordinação. No entendimento de Maurício Godinho Delgado (2007a, p. 334), "autonomia e subordinação são conceitos antitéticos, contraditórios", logo, se existe autonomia, não existe a possibilidade de se configurar a subordinação.

A autonomia existente no caso em questão, no entanto, não é plena, devido ao formato de atuação da empresa Uber, que define os valores cobrados pelas corridas realizadas, de modo unilateral e imposto. Dessa forma, convém analisar outras formas de subordinação, como a estrutural.

A subordinação estrutural, também conhecida por subordinação integrativa, conforme diz Maurício Godinho Delgado, configura-se na situação de inserção do trabalhador na dinâmica do tomador de serviços, independentemente da existência de ordens diretas proferidas pelo empregador (DELGADO, 2007b). Leva-se em conta apenas o acolhimento pelo trabalhador, estruturalmente, da dinâmica de organização e funcionamento da empresa. 
No caso da empresa Uber, a empresa fornece uma plataforma sem a qual o trabalho não pode ser exercido. O trabalhador pode se utilizar de plataformas de outras empresas, subsumindo-se à estrutura organizacional de cada uma delas. Dessa forma, existe subordinação estrutural, podendo ainda ser entendida a subordinação no seu sentido clássico, caso se observe a existência de um código de conduta, além da possibilidade de "demissão" por meio de políticas de controle de qualidade da empresa e da definição unilateral dos valores a serem pagos pelos passageiros que utilizam dos serviços prestados.

Uma vez que se entende pela configuração do vínculo empregatício, com o preenchimento dos requisitos contidos na CLT, faz-se necessário mencionar a questão dos riscos da atividade laboral. Os motoristas da empresa Uber assumem todos os riscos no desempenho da atividade, da mesma forma que os taxistas, devendo arcar com valores de manutenção do veículo, combustíveis, entre outros.

Contudo, o art. $2^{\circ}$ da CLT prevê que o risco da atividade deve ser suportado pelo empregador e, no contexto em análise, observa-se que os riscos seriam suportados pelo empregado, o que contrariaria o disposto na legislação. Assim sendo, questiona-se a possibilidade de a relação jurídica em análise tratar-se de uma relação autônoma, consubstanciada em um sistema de parceria entre a empresa Uber e os motoristas.

A relação de trabalho autônoma, conforme esclarece Vólia Bomfim Cassar (2014, p. 276), trata-se de relação onde o trabalhador exerce ofício ou profissão com habitualidade, por sua conta e risco próprio. Cassar defende que a relação de trabalho autônoma, permite, ainda, a existência de subordinação, mesmo que mitigada, conforme ocorre no caso de representantes comerciais (CASSAR, 2014). Em contraposição a Cassar, Maurício Godinho Delgado (2007a) não identifica, na figura do trabalhador autônomo, a presença de subordinação entre o trabalhador e o tomador de serviços, uma vez que considera a ausência de subordinação - a autonomia - como critério essencial para a configuração do trabalho autônomo.

A empresa Uber não exerce controle de jornada, podendo o motorista determinar sua própria jornada de trabalho, inclusive recusar a prestação de trabalho. Ao permitir certa autonomia, a relação de trabalho entre os motoristas e a e Uber poderia ser caracterizada como autônoma.

Quanto à concentração dos riscos da atividade na figura do trabalhador, entende-se que este critério se torna essencial para a definição da relação de trabalho do motorista da 
Uber. Apesar de presentes os requisitos essenciais, quais sejam, pessoa física, pessoalidade, subordinação, não eventualidade e onerosidade, a questão do risco da atividade afastaria a possibilidade de caracterização de relação de emprego entre a empresa Uber e motoristas parceiros. No entendimento de Vólia Bomfim Cassar (2014), se o trabalhador corre o risco do negócio, não há que se falar em relação de emprego.

Com tantas possibilidades, os trabalhadores parecem estar em uma área fronteiriça entre a relação de emprego a relação autônoma. Vólia caracteriza esses trabalhadores como situados na "zona grise", ou seja, uma área cinza de indefinição jurídica (CASSAR, 2014, p. 264). Os motoristas por aplicativo, desassistidos de uma definição concreta da natureza de sua atividade, parecem se situar nessa zona. Possuem características de trabalho autônomo, como os taxistas, assim como de relação de emprego e ainda de trabalho eventual, quando ausente o quesito da não eventualidade. A decisão acerca da existência ou não de vínculo de emprego dependerá do entendimento do julgador em cada caso concreto (CASSAR, 2014).

No Brasil, ainda não existe jurisprudência consolidada sobre a matéria; apenas decisões de primeira instância acerca da natureza jurídica da relação entre motoristas e a empresa. O estudo a seguir apresentado, visando lançar luzes à controvérsia em debate, diz respeito a duas sentenças prolatadas em diferentes ações trabalhistas, uma proposta na cidade de São Paulo e outra no Distrito Federal, ambas em face da empresa Uber.

\section{ANÁLISE DE JULGADOS}

Os julgados a seguir foram selecionados para exemplificar como os julgadores têm abordado a questão do vínculo empregatício dos motoristas por aplicativo com a empresa Uber. Até o presente momento, são escassas as sentenças sobre a matéria, não havendo ainda decisões dos tribunais superiores acerca do assunto. Dessa forma, foram selecionados dois julgados, um de São Paulo e outro do Distrito Federal, cujas decisões foram contrárias e prolatadas com apenas uma semana de diferença. Pela proximidade dos casos, considera-se fecundo levantar o entendimento dos magistrados, para melhor elucidar a questão do trabalho dos motoristas por aplicativo.

Além das decisões analisadas na sequência, outras ações trabalhistas que visam caracterizar motoristas como empregados da empresa Uber foram julgadas. Como exemplo, tem-se a ação $n^{\circ}$ 0011359-34.2016.5.03.0112, com sentença favorável à existência do vínculo 
empregatício, prolatada pelo juiz Márcio Toledo Gonçalves, da 33ª Vara do Trabalho de Belo Horizonte; e a ação no 0011863-62.2016.5.03.0137, com sentença prolatada pelo juiz Filipe de Souza Sickert, da $37^{\text {a }}$ Vara do Trabalho de Belo Horizonte, contrária à existência de vínculo.

O primeiro julgado em análise trata-se de uma sentença trabalhista proferida pelo magistrado Eduardo Rockenbach Pires, juiz do trabalho Substituto da $13^{\mathrm{a}}$ Vara do Trabalho de São Paulo nos autos da ação trabalhista no 1001492-33-2016-5-02-0013, em 11 de abril de 2017. A ação trabalhista proposta pelo reclamante, Fernando dos Santos Teodoro, em face da empresa reclamada (Uber do Brasil Tecnologia Ltda., Uber International BV e Uber International Holding BV), versa sobre pedido de declaração da existência de vínculo empregatício entre o reclamante e a reclamada, com o consequente pagamento das verbas trabalhistas devidas. O magistrado julgou a ação parcialmente procedente.

O segundo julgado a ser analisado trata-se de sentença trabalhista proferida por Tamara Gil Kemp, juíza do trabalho titular da $10^{\text {a }}$ Vara do Trabalho de Gama, no Distrito Federal, nos autos da ação no 0001995-46.2016.5.10.0111, em 18 de abril de 2017. A ação trabalhista foi proposta por William Miranda da Costa, que também buscava a caracterização do vínculo empregatício com a empresa Uber. A magistrada julgou improcedente a ação trabalhista, conforme será discutido adiante.

\subsection{Decisão da Justiça do Trabalho de São Paulo}

A sentença proferida pelo magistrado Eduardo Rockenbach Pires, juiz do trabalho substituto da $13^{\mathrm{a}}$ Vara do Trabalho de São Paulo, inicia com discussão da competência material da ação trabalhista proposta.

A empresa reclamada alegou, em preliminar, que a natureza do contrato com o motorista é de natureza civil, não se tratando de uma relação de trabalho, cujo fundamento afastaria a competência da Justiça do Trabalho. No entendimento do magistrado, a competência material deve ser aferida em função da causa de pedir. No caso, como a causa de pedir é referente à relação jurídica do trabalho, caracteriza a competência material da justiça do trabalho, conforme dispõe o artigo 114, inciso I, da Constituição Federal, independentemente da situação de fato, pois a análise específica do ocorrido já seria análise de mérito. Rejeitou, assim, a preliminar de mérito (BRASIL, 2017a). 
O magistrado declarou a petição inicial inepta quanto a dois pedidos do reclamante: os pedidos de horas extras e adicional noturno. O reclamante alegou que possuía jornada de trabalho superior a 44 horas semanais, em horário diurno e noturno, mas não apresentou provas, nem quantificação das horas de trabalho ou jornada de trabalho média, razão pela qual os pedidos foram declarados ineptos (BRASIL, 2017a).

A empresa Uber fez a solicitação de ofício à Receita Federal para que esta fornecesse a declaração de renda do reclamante, a fim de verificar a existência de outra profissão desempenhada por ele, o que afastaria a existência de vínculo com a Uber, no entendimento da empresa. O magistrado negou o pedido, uma vez que existência de relação de emprego independe de exclusividade na prestação de serviços (BRASIL, 2017a).

Os principais argumentos extraídos desse caso abordam a questão da relação de trabalho existente. O julgado apresenta a análise quanto à suposta relação de emprego, demonstrando a visão do reclamante e da reclamada.

Os argumentos do reclamante para o reconhecimento de vínculo de emprego são, entre outros: existência de onerosidade, uma vez que a empresa retém uma taxa de 25 a $30 \%$ do valor da corrida realizada pelo motorista; existência de um contrato de adesão; controle da empresa concernente às desempenhadas por meio do aplicativo; fixação das tarifas unilateralmente pela reclamada; existência de um sistema de avaliação, o que caracterizaria o poder disciplinar de empregador; a imposição de padrões de conduta e vestimenta na realização do trabalho pela empresa; além da possibilidade de desligamento unilateral a qualquer momento por parte da reclamada, como ocorreu na situação examinada, sem prévio aviso pela reclamada (BRASIL, 2017a).

A empresa Uber, por outro lado, contesta a existência do vínculo, arguindo que: inexiste relação de trabalho, pois a empresa não explora serviços de transporte, e sim oferece um serviço de tecnologia que conecta passageiros e motoristas; não contrata motoristas, nem possui frota de veículos; os clientes da empresa são os motoristas, não os consumidores que utilizam dos serviços; apenas oferece a plataforma, não o serviço de transporte; existência de outras empresas no mesmo segmento no país; inexistência de exclusividade com a plataforma; os horários de trabalho são decididos pelos motoristas; no caso em questão, o reclamante prestou os serviços de motoristas eventualmente, como complemento de renda, uma vez que possui outro emprego; os requisitos legais para a configuração de uma relação de emprego não estão presentes; a ausência de pessoalidade, sendo que o motorista pode se cadastrar em 
outros aplicativos; os motoristas podem se desligar da plataforma, sem penalidades; a Uber não avalia o desempenho dos motoristas, apenas os passageiros que fazem a avaliação; não existe subordinação estrutural, pois o motorista é cliente da empresa e não prestador de serviços; o risco da atividade é suportado pelo trabalhador (manutenção do veículo e despesas com combustível); e inexistência de onerosidade, pois é o motorista quem paga à Uber pela utilização da plataforma, em um sistema de parceria (BRASIL, 2017a).

Quanto aos argumentos levantados por ambas as partes, decidiu o magistrado que, incialmente, deve se entender a questão da atividade empresarial da reclamada. A empresa Uber, conforme atesta o juiz, afirma que possui modelo baseado na economia de compartilhamento, que seu produto é apenas a plataforma que permite a conexão entre motoristas e passageiros (BRASIL, 2017a). No entanto, o magistrado entendeu que o produto principal oferecido pela empresa é o transporte de passageiros, sendo o aplicativo apenas um instrumento para realização do serviço (BRASIL, 2017a).

Dessa feita, os consumidores do produto oferecido pela Uber seriam os passageiros, e não os motoristas. A questão reside em qual é a mercadoria da qual a Uber extrai seus rendimentos, o que, no caso do modelo adotado pela empresa, a mercadoria é o serviço de transportes, conforme o julgado (BRASIL, 2017a). Ao fixar o preço das corridas, não permitindo a Uber que o passageiro e o motorista acordem quanto aos valores, verifica-se a confirmação do entendimento do magistrado de que o produto da empresa é o transporte, e não a plataforma.

Com essa definição, o magistrado confirma que a relação existente é uma relação de trabalho. Superada tal análise, o magistrado discute qual o vínculo existente, analisando os requisitos caracterizadores da relação de emprego, extraídos dos artigos $2^{\circ}$ e $3^{\circ}$ da CLT. Conclui o julgador, portanto, pela existência dos requisitos da pessoa física; da pessoalidade, não podendo o motorista se fazer substituir; e da onerosidade, ao passo que não é o motorista quem paga à empresa pela utilização da plataforma, mas sim a Uber quem remunera o motorista, através do repasse dos valores recebidos dos passageiros (BRASIL, 2017a).

Quanto a não eventualidade da prestação de serviços, a caracterização de tal requisito depende da análise do caso em questão, não bastando o exame do modelo de trabalho existente. No caso em debate, asseverou o magistrado inexistir provas da eventualidade da prestação laboral pelo reclamante, presumindo-se, pois, a prestação de trabalho não eventual pelo motorista (BRASIL, 2017a). 
A subordinação é uma das questões mais controvertidas. Para o magistrado, a subordinação está presente, diante do entendimento de que empreendimento como um todo é da empresa reclamada, e não negócio do motorista (BRASIL, 2017a). Além disso, o fato do preço do serviço final ser estabelecido unilateralmente pela reclamada, a existência de controle dos indicadores de demanda e oferta dos seus serviços no mercado e a política da taxa de cancelamentos encaminham para a caracterização do requisito da subordinação (BRASIL, 2017a).

Conclui o magistrado, portanto, pela existência de vínculo empregatício, deferindo o pedido de anotação na Carteira de Trabalho e Previdência Social (CTPS) do reclamante, além das verbas rescisórias devidas. Ainda, rejeita o magistrado a justa causa, uma vez que, conforme dispõe no artigo 482 da CLT, tal instituto decorre de ato doloso ou culposamente grave do empregado, o que não se concretizou na prática, tendo em vista que a Uber não comprovou gravidade da situação (BRASIL, 2017a).

Importa ainda mencionar, a condenação impingida pelo magistrado em face da Uber, ao condená-la ao pagamento de indenização por danos morais ao motorista:

A atuação agressiva da ré no tocante ao ganho de mercado e ao barateamento de mão de obra esbarra em preceitos constitucionais, notadamente os direitos fundamentais dos trabalhadores $\mathrm{e}$ a valorização do trabalho como fundamento da ordem econômica. Tais normas basilares vedam o uso do ser humano como mercadoria de comércio ou como insumo da produção, o que na prática vem sendo feito pela ré. Existe aí uma clara violação ao princípio da dignidade humana. (BRASIL, 2017a, p. 15).

Dessa forma, o deferimento da pretensão indenizatória, balizado pelo porte econômico da Uber, assume tanto o caráter compensatório como o pedagógico, visando impedir reincidências.

\subsection{Decisão da Justiça do Trabalho do Distrito Federal}

O primeiro ponto abordado na sentença proferida pela juíza titular do trabalho Tamara Gil Kemp, da $10^{\text {a }}$ Vara do Trabalho de Gama, no Distrito Federal, diz respeito à pretensão declaratória de incompetência material da ação ajuizada. Assim como no julgado anterior, a empresa Uber alegou que a relação jurídica com os motoristas deu-se apenas em caráter comercial, qual seja, a de prestação de serviços de intermediação por meio da 
plataforma Uber. A magistrada negou tal pedido, tendo em vista que o artigo 114, inciso I, da Constituição Federal dispõe ser competente a Justiça do Trabalho para julgar ações oriundas de relação de trabalho, além de controvérsias dela decorrentes, na forma da lei, da mesma forma como o entendido pelo magistrado de São Paulo (BRASIL, 2017b).

Quanto ao reconhecimento do vínculo de emprego, o reclamante alegou que foi contratado pela empresa Uber sem registro na CTPS, para desempenhar a função de motorista executivo, sendo dispensando sem justa causa e sem recebimento de verbas rescisórias (BRASIL, 2017b). A empresa Uber, por outro lado, alega que o reclamante não atuou como empregado, e sim como parceiro, detendo autonomia e liberdade na atuação profissional e intelectual. O motorista apenas teria contratado os serviços de intermediação da plataforma Uber para viabilizar o transporte de passageiros (BRASIL, 2017b).

Expõe a magistrada no julgado que a CLT não exige que o empregado preste serviços com exclusividade para a caracterização do vínculo de emprego. No entanto, ressalta que, inexistentes os requisitos previstos na CLT (subordinação jurídica, habitualidade, pessoalidade e onerosidade), improcede o reconhecimento do vínculo empregatício (BRASIL, 2017b).

No caso em questão, entendeu a magistrada que o reclamante possuía total liberdade em sua atividade laborativa, não se submetendo a horários ou a qualquer controle por parte da empresa Uber (BRASIL, 2017b). A juíza não encontrou indícios ou provas de ordens, horários, punições ou submissões de qualquer natureza que demonstrassem existir subordinação. Como exemplo, utilizou o fato de o motorista poder desligar o aplicativo, ou seja, não trabalhar, e não ser punido por isso (BRASIL, 2017b).

Entendeu a magistrada que o reclamante trabalhava na condição de parceiro, dividindo os ganhos e com autonomia para escolher quando atuar, inexistindo, portanto, subordinação (BRASIL, 2017b). Também contribui para esse entendimento, segundo a juíza, o fato de que o motorista retinha $75 \%$ do total arrecadado, remuneração que representa mais da metade dos serviços prestados, que no entendimento da juíza não pode ser enquadrado dentro do conceito de salário (BRASIL, 2017b). Além disso, a juíza rejeitou a tese de que a empresa Uber exercia qualquer tipo de pressão para que o motorista continuasse trabalhando, sobretudo através do envio de mensagens informando sobre os valores recebidos (BRASIL, 2017b). 
Diante do conteúdo fático-probatório, a magistrada declarou que os fatos alegados pelo motorista são insuficientes para a caracterização do vínculo empregatício, pois o trabalho exercido não se caracteriza como uma típica relação de emprego, diante da inexistência dos correspondentes requisitos caracterizadores. Desta feita, julgou improcedente a ação, caracterizando a prestação como trabalho autônomo (BRASIL, 2017b).

\subsection{Análise comparativa dos julgados}

Observam-se, pela análise dos julgados, algumas similaridades e, principalmente, controvérsias. Importante ressaltar que as questões abordadas nos julgados analisados não podem ser generalizadas, uma vez que ainda inexiste jurisprudência consolidada sobre a matéria na Justiça do Trabalho. Podem ser extraídas, contudo, algumas ponderações pertinentes.

Ambos os julgados tratam da questão do vínculo empregatício de motoristas da Uber, porém, em contextos diferentes (por exemplo, cidade de atuação). O que importa para a presente análise são os requisitos acerca da caracterização do vínculo de emprego quanto à forma de trabalho adotada pela empresa Uber.

Um dos primeiros requisitos analisados, a subordinação, apresenta divergências em ambos os julgados. A dificuldade, como anteriormente mencionado, de se verificar a subordinação no modelo adotado pela Uber parte do fato de que o trabalho dos motoristas possui certa flexibilidade e autonomia, podendo conduzir ao entendimento de que a subordinação jurídica, em seu sentido clássico, não se encontraria presente.

A Justiça do Trabalho de São Paulo entendeu que a subordinação está presente, contribuindo para o entendimento de que o motorista por aplicativo é empregado da Uber. A Justiça do Trabalho do Distrito Federal, no julgado em análise, entendeu o oposto, ou seja, que existe autonomia na relação de trabalho e, desta feita, não poderia ser configurada relação de emprego, pela falta da subordinação. O motorista seria, então, trabalhador autônomo.

Além da subordinação, há também controvérsia quanto ao requisito da onerosidade. No caso do primeiro julgado apresentado, a onerosidade se configura pela existência de contraprestação, caracterizada através do pagamento pela empresa ao motorista, com retenção de porcentagens. Todavia, confere-se no segundo julgado que essa mesma contraprestação não caracteriza salário, afastando, portanto, o requisito da onerosidade. 
Ambos os entendimentos encontram respaldo tanto na legislação como na doutrina. Todavia, a dificuldade de se enquadrar o trabalho dos motoristas por aplicativo em uma das formas de trabalho conhecidas, dadas as suas peculiaridades, pode desencadear divergências quanto à caracterização dos requisitos da relação de emprego, conforme analisado anteriormente.

Essa situação de indecisão quanto à espécie de relação de trabalho correspondente (relação de emprego ou trabalho autônomo) contribui para que esses trabalhadores permaneçam em uma área fronteiriça, ou seja, alguns terão direitos trabalhistas enquanto outros não os terão. Dessa forma, criam-se condições para que os motoristas por aplicativo permaneçam à margem dos direitos trabalhistas já reconhecidos para outras categorias de trabalhadores, como, por exemplo, ao FGTS e aos benefícios da Previdência e da Seguridade Social decorrentes das contribuições previdenciárias.

Ao se analisar o contexto do trabalho dos motoristas da empresa Uber, verifica-se que tais trabalhadores estão suscetíveis a um modelo laboral que comporta abusos, como, por exemplo, jornadas excessivas, diante da inexistência de limitação da duração do trabalho, como no caso analisado que tramitou perante a Justiça do Trabalho de São Paulo, cuja jornada discutida superava as 44 horas semanais (BRASIL, 2017a). Tais condições podem culminar em precarização das condições laborais e em riscos aos consumidores do serviço, sobretudo em situações de fadiga do motorista pelo excesso de trabalho.

\section{CONSEQUENCIAS PARA O DIREITO DO TRABALHO DO MODELO DA UBER}

A empresa Uber apresenta um modelo de trabalho peculiar, apresentando vantagens econômicas tanto para trabalhadores como para consumidores, que passaram a contar com um serviço de transportes dotado de facilidades não ofertadas pelos taxistas, mesmo em tempos de sofisticação tecnológica. Este modelo tem se expandido, sendo conhecido atualmente como "Uberização" econômica.

A uberização apresenta como características a utilização de uma plataforma digital, que permite a conexão entre usuários e a consequente redução da distância entre o motorista e o consumidor, além da utilização de um sistema que permite o controle da qualidade dos serviços prestados. Outras empresas além da Uber passaram a adotar esse modelo de trabalho, como a Lyft e Cabify (setor de transporte urbano) e a AirBnb (setor de hospedagem). Outros 
sistemas, como Netflix e Spotify partem dos mesmos princípios, ao facilitarem o contato entre produtores de conteúdo e o público.

Apesar das vantagens oferecidas aos trabalhadores pela Uber, este modelo também pode culminar em precarização do trabalho e dos direitos destes trabalhadores. A empresa Uber obtém vantagens e se encontra num patamar mais elevado da relação, em decorrência do seu poder unilateral de decisão. O motorista, por sua vez, fica à mercê do sistema fornecido pela empresa, devendo seguir suas diretrizes para que possa continuar se utilizando da plataforma para trabalhar.

A empresa Uber, assim como ressalta o juiz Eduardo Rockenbach Pires, atua agressivamente, colocando em risco direitos fundamentais dos trabalhadores (BRASIL, 2017a). Os motoristas da Uber são tratados como "clientes", "parceiros" ou "insumo de produção", sem possuir qualquer direito assegurado. Prova disso é a política de desligamento unilateral da Uber, que possibilita "demissões" por não se manter o trabalhador dentro da qualidade esperada pela empresa, o que ocorreu nos julgados analisados. Tal situação, na visão do magistrado Eduardo Rockenbach Pires viola o princípio da dignidade humana (BRASIL, 2017a).

Esse entendimento, contudo, deve ser observado conjuntamente com o fato de que os trabalhadores aceitam, por vontade própria, permanecerem nesse setor, por nele identificarem vantagens econômicas. Aponta Arun Sundararajan (2016) que nos Estados Unidos, ainda que alguns motoristas se sintam violados em seus direitos, a vasta maioria de trabalhadores autônomos não deseja mudar sua condição de trabalho, segundo se verificou em um estudo realizado em 2005 pelo Government Accountability Office (GAO), organização independente que trabalha junto ao Congresso Americano (SUNDARARAJAN, 2016). Para Arun (2016), apesar disso, essa situação não demonstra que esses trabalhadores não desejem benefícios associados aos empregados típicos.

De acordo com Sundararajan (2016), a tendência é de aumento da força de trabalho no setor nos próximos anos. Aduz ainda que, apesar de existirem trabalhadores da sharing economy que dependem exclusivamente apenas das plataformas digitais como fonte de renda, uma parcela desses trabalhadores já possui uma renda ou certa estabilidade econômica, apenas desejando uma gratificação extra (SUNDARARAJAN, 2016).

O problema da expansão do setor dos motoristas por aplicativo e de outros que adotem o mesmo modelo, esbarra na existência de leis trabalhistas específicas para o setor. 
Arun Sundararajan (2016) questiona se as leis existentes atualmente estão preparadas para lidar com os desafios propostos por esse novo mercado de trabalho ou se poderiam criar barreiras para o setor.

Segundo Sundararajan (2016), com as ameaças de processos trabalhistas nos Estados Unidos, empresas do setor têm reclassificado seus trabalhadores como empregados em tempo parcial segundo as leis locais, buscando evitar problemas para o novo setor que se inicia, em troca de impor restrições para o modelo de trabalho original.

Classificar os motoristas por aplicativo como simples empregados pode acabar por reduzir a potencialidade do mercado de trabalho em plena ascensão. Em uma situação de crises econômicas, com o aumento do desemprego em várias localidades, é de se questionar a inviabilização de novos formatos de trabalho e a consequente geração de oportunidades. Por isso, defende Sundararajan (2016) a criação de uma nova categoria de relação de trabalho nos Estados Unidos, não totalmente desprovida de uma proteção jurídica, para melhor atender às necessidades e anseios desse novo mercado. Em suma, existe a necessidade de garantir condições dignas de trabalho para estes trabalhadores e, concomitantemente, estimular o desenvolvimento do setor (SUNDARARAJAN, 2016, p. 184).

A classificação dos motoristas por aplicativo como empregados ou como outra espécie de trabalhador (por exemplo, autônomo) pode desencadear impactos não só na seara trabalhista como também em outras áreas relacionadas (por exemplo, tecnologia da informação), cuja medida deve ser realizada com cautela (SUNDARARAJAN, 2016). Não obstante, é preciso enfrentar os dilemas quanto à possibilidade de serem elaborados mecanismos flexíveis e, ao mesmo tempo, protetivos, sem deixar de se atentar para o trabalhador, reconhecidamente o sujeito mais vulnerável da relação laboral.

Criar medidas de harmonização entre as novas possibilidades de trabalho e a tutela dos direitos fundamentais mínimos dos trabalhadores, torna-se um desafio para o Direito do Trabalho no cenário contemporâneo. Segundo Arun, é o início da transição do trabalho para a economia colaborativa, o que impossibilita a criação de leis trabalhistas específicas. Isso porque, geralmente, legislações trabalhistas duram décadas, e a inexistência de dados suficientes sobre o trabalho na economia colaborativa dificulta a elaboração de medidas em longo prazo (SUNDARARAJAN, 2016).

A economia colaborativa demonstra não ser uma onda passageira. Adequar o Direito do Trabalho a esse novo mercado se torna essencial para o desenvolvimento econômico. Não 
basta, contudo, simplesmente a criação de uma legislação que se adapte ao momento atual, mas, sim, de mecanismos que possam ser moldados à medida que os modelos de trabalho se desenvolvem e seus problemas se tornem visíveis.

O modelo de trabalho da Uber, possibilitado pela sharing economy, tem um grande potencial econômico, com efeitos que tendem a crescer e se espalhar por diversas áreas. Cabe, como desafio ao Direito do Trabalho e aos seus operadores, compreender essa nova lógica. Classificar precipitadamente os motoristas da Uber como autônomos ou como empregados pode inviabilizar uma forma de prestação de serviços que ainda se encontra em desenvolvimento, afetando empresas e trabalhadores, além de consumidores.

No Brasil, o Ministério Público do Trabalho (MPT) do Rio de Janeiro e de São Paulo abriu ainda inquéritos com o objetivo de averiguar possíveis fraudes às leis trabalhistas cometidas pela empresa Uber. Para o procurador do trabalho Rodrigo Carelli, que atua nos inquéritos instaurados na cidade do Rio de Janeiro, a análise inicial demonstra existência de uma fraude trabalhista que, caso se comprove, poderá ensejar a contratação de todos os motoristas pela empresa como empregados, além da condenação do pagamento de dano moral coletivo pela Uber (COURA; SCOCUGLIA, 2016).

Após todas as considerações construídas ao longo deste estudo, persiste a questão se a contratação coletiva desses motoristas, com reconhecimento do vínculo empregatício, seria o melhor caminho para a proteção destes trabalhadores em atenção aos preceitos legais, ou se tal medida poderá gerar impactos negativos no setor.

Ainda assim, é precária a situação atual dos trabalhadores da Uber, posto que residem em um estado de indefinição quanto à natureza jurídica dessa forma de trabalho, o que justifica a necessidade de medidas que conciliem direitos e deveres de ambas as partes da relação jurídica analisada. Ao Direito do Trabalho cabe evitar que esses trabalhadores se tornem reféns de uma estrutura econômica totalmente assimétrica, cujas vantagens econômicas são evidentes, defendendo os direitos fundamentais dos trabalhadores e sempre visando à proteção da dignidade humana, sem, contudo, limitar o setor e, por consequência, contribuir para a sua extinção.

\section{CONSIDERAÇÕES FINAIS}


O estudo apresentado se propôs a discutir a relação jurídica existente entre motoristas por aplicativo e a empresa Uber, além das consequências dessa relação sob a perspectiva do Direito do Trabalho. Discutiram-se, ainda, possíveis violações a direitos fundamentais que esse modelo laboral pode desencadear, incluindo a precarização dessa forma de trabalho.

Sabe-se que a economia colaborativa propiciou o surgimento de novas interações e, consequentemente, de novas formas de trabalho. Apesar do modelo de organização da empresa Uber se afastar da ideia de colaboração defendida pela sharing economy, o cerne de sua atuação se encontra no fenômeno colaborativo, ao possibilitar que qualquer indivíduo compartilhe seu veículo e força de trabalho com outra pessoa (no sistema de motorista parceiro), em troca de uma remuneração, a princípio paga diretamente pelos passageiros. Contudo, é evidente que essa concepção se altera, tendo a empresa Uber desenvolvido um modelo de trabalho que, apesar de novo, demonstra indícios de ser apenas uma relação de emprego tradicional, de exploração de mão de obra.

A análise do modelo laboral em questão permite compreender que o trabalho se adapta para atender às novas exigências do mercado. Apesar de possuir todos os indícios de uma típica relação de emprego, o modelo inaugurado pela Uber também apresenta flexibilidade e autonomia. A dificuldade de identificação quanto à natureza dessa relação de trabalho, em razão de seus contornos genuínos e inovadores, conduz a entendimentos diversos acerca da mesma forma de trabalho.

Todavia, diante da ausência de regulamentação dessa forma de trabalho, bem como de políticas públicas direcionadas a esse novo segmento, tais trabalhadores permanecem em um estado de indefinição e desprovidos de proteção juslaboral. Trata-se de situação grave sob o ponto de vista jurídico e social, pois a precarização dessa atividade laboral pode estimular a exploração dos trabalhadores pela empresa e a violação de princípios fundamentais, mormente o da dignidade da pessoa humana.

Isso porque é através do trabalho que o indivíduo se desenvolve, tanto na perspectiva pessoal como na social, cujo fenômeno - o do desenvolvimento humano - não se limita apenas a um viés econômico, ou seja, à percepção de remuneração visando à satisfação das necessidades humanas mais primárias. O trabalho e seu contexto é, portanto, arena e motor do desenvolvimento humano. Daí dizer que, com a economia colaborativa, o trabalho adquire uma dinâmica mais solidária, reforçando o seu caráter social. De tal sorte, a exploração indiscriminada do trabalho humano pelo modelo adotado pela empresa Uber, produz 
implicações em diversas dimensões do cotidiano do trabalhador, podendo ainda impactar em sua saúde e em seu bem-estar, dentro e fora do contexto laboral.

Ignorar a precarização dessa forma de trabalho, assim como adotar regulações que inviabilizem o setor, pode afetar negativamente essa nova categoria de trabalhadores. $\mathrm{O}$ desenvolvimento de políticas públicas que visem à proteção dos direitos trabalhistas desses motoristas, ainda que mínima, levando-se em conta também o desenvolvimento do setor, possibilitaria garantir condições dignas a esses trabalhadores. Permitirá, ainda, efetivar os princípios fundamentais contidos na Constituição Federal de 1988, quais sejam, a dignidade da pessoa humana, os valores sociais do trabalho e da livre iniciativa; além de contribuir para o crescimento sustentável desse modelo de trabalho do país, cujos impactos econômicos não podem ser ignorados.

\section{REFERÊNCIAS}

BRASIL. Tribunal Regional do Trabalho da $2^{\text {a }}$ Região. Sentença trabalhista na Reclamação Trabalhista 1001492-33-2016-5-02-0013. Juiz: Eduardo Rockenbach Pires. Prolatada em 11 abr. 2017. Disponível em: <https://d2f17dr7ourrh3.cloudfront.net/wpcontent/uploads/2017/04/Sentença-Uber.SP-Vínculo.pdf>. Acesso em: 21 abr. 2017a.

Tribunal Regional do Trabalho da $\mathbf{1 0}^{\mathbf{a}}$ Região. Sentença trabalhista na Reclamação Trabalhista 0001995-46.2016.5.10.0111. Juíza: Tamara Gil Kemp. Prolatada em 18 abr. 2017. Disponível em: 〈http://s.conjur.com.br/dl/uber-decisao.pdf〉. Acesso em: 21 abr. $2017 b$.

CASSAR, Vólia Bomfim. Direito do Trabalho. 10. ed. rev., atual. e ampl. São Paulo: Método, 2014.

COURA, Kalleo; SCOCUGLIA, Livia. Uber enfrenta primeiros processos trabalhistas no Brasil. Jota Info, 09 set. 2016. Disponível em: <http://jota.info/o-uber-e-lei-motoristas-vaojustica-para-pleitear-vinculo-empregaticio?cmpid=fb-uolnot>. Acesso em: 8 maio 2017.

DELGADO, Maurício Godinho. Capitalismo, trabalho e emprego: entre o paradigma da destruição e os caminhos de reconstrução. 2. ed. São Paulo: LTr, 2015.

Curso de direito do trabalho. 6. ed. São Paulo: LTr, 2007a. 
Direitos fundamentais na relação de trabalho. Revista de Direitos e Garantias

Fundamentais, n. 2, 2007b. Disponível em:

<http://www.fdv.br/publicacoes/periodicos/revistadireitosegarantiasfundamentais/n2/1.pdf $>$. Acesso em: 7 maio 2017.

KERR, Vera. Uber X Táxi - A nova velha economia. Sumário de Pesquisa, v. 1, n. 1, out. 2015. Disponível em: <http://www.cest.poli.usp.br/wp-

content/uploads/sites/26/2016/03/V1N1pt_uber.pdf>. Acesso em: 10 maio 2017.

PARCEIROSBR. Apresenta informações acerca do funcionamento da empresa UBER, 2015. Disponível em: <http://www.parceirosbr.com/>. Acesso em: 8 maio 2017.

SUNDARARAJAN. The Sharing Economy: the end of employment and the rise of crowdbased capitalism. Cambridge, MA: The MIT Press, 2016.

UBER NEWSROOM. Fatos e dados sobre a Uber, 14 jan. 2015. Disponível em:

<https://newsroom.uber.com/brazil/fatos-e-dados-sobre-a-uber/>. Acesso em: 8 maio 2017.

UBER. Apresenta informações para motoristas parceiros, 2016a. Disponível em: <https://www.uber.com/pt/drive/>. Acesso em: 8 maio 2017.

Driver Deactivation Policy, 2016b. Disponível em:

<https://www.uber.com/legal/deactivation-policy/us-multi-lingual/en/>. Acesso em: 13 maio 2017. 